\title{
Editorial
}

\section{Fighting Infections in Developing Countries by Cost-Affordable and Sustainable Means}

In developing areas around the globe it is extremely hard for health related institutions and governments to implement prevention and treatment policies, to improve public health, due to poor economical resources and infrastructures; low awareness; inadequate personnel; high prevalence of parasites and pathogens with extreme infection burdens, as well as sociopolitical factors.

Central government programs essential for the improvement of the general public health are limited in developing countries. These include mass vaccination programs, which are cornerstones of primary health-care [1]; programs to reduce waterborne and water-associated vector-borne diseases [2]; routine surveillance activities [3,4]; regulation of pesticide usage (e.g. developing countries use only $20 \%$ of the world's agrochemicals, yet they suffer $99 \%$ of deaths from pesticide poisoning [5]); programs to reduce malnutrition [6]; programs to educate the public (e.g. use of condoms to reduce sexually transmitted diseases); and funding of medical care.

However, the high disease rate itself possesses a very significant economic burden on developing countries. This burden exacerbates the incapacity of the governments to address the critical need for better health care. For example, malaria alone costs sub-Saharan Africa US\$100 billion in lost annual gross domestic product (GDP) [1]. The combination of high infection rates together with poor public health care has become a vicious cycle that needs to broken.

While in developed countries prevention and treatment modalities have significantly improved public health, the standard of living and life expectancy [1,7-9], this is not the case in developing countries, where the improvement of health care is multifaceted and extremely complicated. Assistance from world organizations together with the developed and affluent countries is essential. However, it has to be taken into consideration that solutions that have been successful in developed countries may not be appropriate for those that are developing. For example, vaccines that may confer protection against HIV-1 in Europe and USA, may fail to do so in Africa and other developing countries due to the significantly different pre-existing immune background of the population [10-12]. Another problem is the extremely high illiteracy and poverty rate that prevails in many rural areas in these countries. Thus, simple, cost affordable, wide spectrum, immediate and applicable means, which accommodate the particular constraints of developing countries, must be developed and applied in order to specifically and rapidly address key issues of public health in these volatile regions.

The current Hot Topic issue presents several cost-affordable and sustainable means that may help fight the high infections rates in developing countries. Doucoure and Farcy propose novel membrane systems that can be applied in small rural communities and remote areas in developing countries aimed at reducing water-borne diseases and pollutants. Borkow and Gabbay suggest the use of biocidal textiles in hospitals in order to reduce the high rates of nosocomial infections. Togo and his colleagues from a hospital in Bamako - Mali make a robust attempt to identify the causes of nosocomial infections in a developing country and recommend measures aimed at reducing these infections in hospital settings. Ole Skovmand discusses the use of insecticidal bednets for the fight against malaria in developing countries. Finally, Bentwich and colleagues present the hypothesis that the relatively straightforward treatment of helminthic parasites may have very wide ramifications in improving the treatment and prognosis of other diseases, and in enhancing the capacity to achieve effective immunization.

Dr. Gadi Borkow, PhD (Guest Editor)

Hameyasdim 44, Kfar Gibton, 76910, Israel.

Tel: 972-546-611287

Fax: 972-8-9491254

E-mail: gadi@cupron.com 


\section{REFERENCES}

[1] Andre FE, Booy R, Bock HL, et al. Vaccination greatly reduces disease, disability, death and inequity worldwide. Bull World Health Organ 2008; 86: $140-6$.

[2] Batterman S, Eisenberg J, Hardin R, et al. Sustainable control of water-related infectious diseases: a review and proposal for interdisciplinary healthbased systems research. Environ Health Perspect 2009; 117: 1023-32.

[3] Braunstein SL, van de Wijgert JH, Nash D. HIV incidence in sub-Saharan Africa: a review of available data with implications for surveillance and prevention planning. AIDS Rev 2009; 11: 140-56.

[4] May L, Chretien JP, Pavlin JA. Beyond traditional surveillance: applying syndromic surveillance to developing settings--opportunities and challenges. BMC Public Health 2009; 9: 242.

[5] Kesavachandran CN, Fareed M, Pathak MK, Bihari V, Mathur N, Srivastava AK. Adverse health effects of pesticides in agrarian populations of developing countries. Rev Environ Contam Toxicol 2009; 200: 33-52.

[6] Atinmo T, Mirmiran P, Oyewole OE, Belahsen R, Serra-Majem L. Breaking the poverty/malnutrition cycle in Africa and the Middle East. Nutr Rev 2009; 67 (Suppl 1): S40-S46.

[7] Barnighausen T, Bloom DE, Canning D, O'Brien J. Accounting for the full benefits of childhood vaccination in South Africa. S Afr Med J 2008; 98: $842,844-2,846$.

[8] Bloom DE, Canning D, Weson M. The value of vaccination. World Econ 2005; 6: 15-39.

[9] Shearley AE. The societal value of vaccination in developing countries. Vaccine 1999; 17 (Suppl 3): S109-S112.

[10] Borkow G, Bentwich Z. Chronic parasite infections cause immune changes that could affect successful vaccination. Trends Parasitol 2008; 24: 243-5.

[11] Borkow G, Bentwich Z. Chronic immune activation associated with chronic helminthic and human immunodeficiency virus infections: role of hyporesponsiveness and anergy. Clin Microbiol Rev 2004; 17: 1012-30, table.

[12] Borkow G, Bentwich Z. Eradication of helminthic infections may be essential for successful vaccination against HIV and tuberculosis. Bull World Health Organ 2000; 78: 1368-9.

(C) Gadi Borkow; Licensee Bentham Open.

This is an open access article licensed under the terms of the Creative Commons Attribution Non-Commercial License (http://creativecommons.org/licenses/by$\mathrm{nc} / 3.0 /$ ), which permits unrestricted, non-commercial use, distribution and reproduction in any medium, provided the work is properly cited. 